\title{
Inhibition of HGF/cMET expression prevents distant recurrence of rectal cancer after preoperative chemoradiotherapy
}

\author{
SUSUMU SAIGUSA ${ }^{1}$, YUJI TOIYAMA ${ }^{1}$, KOJI TANAKA ${ }^{1}$, TAKESHI YOKOE ${ }^{1}$, HIROYUKI FUJIKAWA ${ }^{1}$, \\ KOHEI MATSUSHITA ${ }^{1}$, YOSHINAGA OKUGAWA ${ }^{1}$, YASUHIRO INOUE ${ }^{1}$, KEIICHI UCHIDA $^{1}$, \\ YASUHIKO MOHRI $^{1}$ and MASATO KUSUNOKI ${ }^{1,2}$
}

Departments of ${ }^{1}$ Gastrointestinal and Pediatric Surgery, and ${ }^{2}$ Innovative Surgery, Division of Reparative Medicine, Institute of Life Sciences, Mie University Graduate School of Medicine, 2-174 Edobashi, Tsu, Mie 514-8507, Japan

Received July 5, 2011; Accepted August 23, 2011

DOI: $10.3892 /$ ijo.2011.1200

\begin{abstract}
Hepatocyte growth factor (HGF) and its receptor cMET play an important role in tumor proliferation, invasion and metastasis. In this study, we investigated the association of HGF/cMET signaling with distant recurrence in rectal cancer after preoperative chemoradiotherapy and whether inhibition of the HGF/cMET signaling pathway could suppress the re-growth of cancer cells after irradiation. We obtained total RNA from residual cancer cells and stromal tissue separately using microdissection from a total of 53 rectal cancer specimens from patients who underwent preoperative CRT, performed transcriptional analyses, and analyzed the association of HGF and cMET expression levels with clinical outcomes. We performed in vitro experiments to examine HGF and cMET expression and the re-growth of cancer cells after irradiation and treatment with a tyrosine kinase inhibitor specific for cMET (SU11274). We found significant correlations between cancer cell HGF and cMET gene expression, and stromal cell HGF and cancer cell cMET expression. Elevated cancer cell cMET and stromal HGF expression were significantly associated with a worse prognosis. In vitro experiments showed that the up-regulation of HGF expression and the re-growth of irradiated cancer cells were effectively suppressed by inhibiting cMET. Our results suggest that inhibition of radiation-induced HGF up-regulation and blockade of autocrine/paracrine HGF/ cMET signaling are potential new strategies for controlling distant recurrence in rectal cancer patients after preoperative CRT.
\end{abstract}

Correspondence to: Dr Susumu Saigusa and Dr Masato Kusunoki, Department of Gastrointestinal and Pediatric Surgery, Division of Reparative Medicine, Institute of Life Sciences, Mie University Graduate School of Medicine, 2-174 Edobashi, Tsu, Mie 514-8507, Japan

E-mail: saigusa@clin.medic.mie-u.ac.jp;

kusunoki@clin.medic.mie-u.ac.jp

Key words: hepatocyte growth factor, cMET, rectal cancer, distant recurrence, preoperative chemoradiotherapy

\section{Introduction}

The introduction of preoperative chemoradiotherapy (CRT) and total mesorectal excision (TME) for the management of rectal cancer significantly decreased local recurrence rates and improved patient survival. However, the rate of distant recurrent relapse still remains as high as $15-20 \%$ in rectal cancer patients treated with preoperative CRT followed by surgery (1-3). The mechanism of distant recurrence after CRT remains a mystery. Further improvements in the rectal cancer survival rate cannot be achieved without improvements in impacting distant recurrence after preoperative CRT. Radiotherapy is an effective tool for local control that works by inducing cancer cell apoptosis and death, in addition to inhibiting cell growth in various malignancies. However, other investigators have shown that radiation promotes cancer cell invasion and metastasis (4-8), and induces epithelial to mesenchymal transition (EMT) (9-11).

Hepatocyte growth factor (HGF) and its receptor cMET are involved in various malignant tumors. HGF/cMET signaling prevents apoptosis through the phosphorylation of phosphatidylinositol-3-kinase and subsequent Akt activation $(12,13)$. A number of reports have identified that the overexpression of HGF and cMET are associated with cancer invasion, metastasis and poor prognosis in various cancers (14-18). HGF, known as a scatter factor, is a mesenchymal cytokine with pleiotropic effects, including mitogenic, motogenic and morphogenic properties, and plays an important role in angiogenesis and tumor growth via promoting angiogenic mediators, including vascular endothelial growth factor (VEGF) (19-21). cMET is the cell surface receptor and the only known functional receptor for HGF. cMET is also associated with the invasion and metastatic progression of cancers $(17,20,22,23)$. HGF is only expressed by cells of mesenchymal origin $(21,24)$. Conversely, cMET is expressed by various cell types, including vascular cells, lymphatic endothelial cells and hematopoietic cells $(14,25,26)$. Although most cancer cells do not express HGF, HGF/cMET interactions are activated in a paracrine manner by stromal cell HGF, which produces a suitable microenvironment for cancer cell growth and invasion, and in an autocrine manner by cMET produced by cancer cells. 
In the last several years, inhibition of the HGF/cMET signaling pathway has been spotlighted as a new target in cancer treatment. Preclinical and clinical studies using different approaches to inhibit HGF/cMET signaling, including competitors of $\mathrm{HGF} /$ cMET, monoclonal antibodies directed against HGF and c-MET and small-molecule tyrosine kinase inhibitors directed against cMET, are now ongoing $(14,27,28)$. SU11274 is small-molecule tyrosine kinase inhibitor of cMET and an ATP-competitor for the catalytic activity of the cMET tyrosine kinase domain. SU11274 has been shown to block HGF-dependent cMET activation and is also effective against mutated variants of MET (29).

We hypothesized that preoperative radiation might promote distant recurrence in rectal cancer. Because we found that HGF mRNA levels were up-regulated by irradiation in our preliminary in vitro studies, we investigated whether inhibition of HGF or cMET before irradiation could suppress the up-regulation of HGF and cell re-growth after irradiation and analyzed the correlation between HGF and cMET expression in residual tumor with distant recurrence and prognosis.

\section{Materials and methods}

Patients and specimens. From 2001 to 2008, 53 patients with rectal cancer received preoperative CRT followed by surgery in our institute (criteria for induction of preoperative CRT in our institute: age 80 years or younger, clinical stage II/III based on the International Union Against Cancer TNM classification, no evidence of distant metastases, no invasion of external sphincter muscle and elevator muscle of anus, and no evidence of deep venous thrombosis). FFPE specimens after CRT were available for this study. Twelve endoscopic tumor biopsy specimens before CRT matched to FFPE specimens were snap-frozen in liquid nitrogen and kept at $-80^{\circ} \mathrm{C}$ until use. All patients signed informed consent forms for their tissues to be used in this study.

5-fluorouracil-based chemoradiotherapy regimen. Patients with rectal cancer were treated in our institution with shortcourse (a dose of $20 \mathrm{~Gy}$ in four fractions) or long-course (a dose of 45 Gy in 25 fractions) radiotherapy using a four-field box technique with concurrent chemotherapy to take advantage of 5-fluorouracil (5-FU) radiosensitization. All patients underwent a computed tomography simulation for threedimensional radiotherapy planning and were treated with a 10-MV photon beam using a linear accelerator. The radiation field encompassed a volume that included the primary tumor, mesorectum, presacral space, whole of the sacral hollow and regional lymph nodes. The superior border was placed at L5/ $\mathrm{S} 1$ and the inferior border was $3 \mathrm{~cm}$ or more caudal to the primary tumor. Patients underwent concurrent pharmacokinetic modulation chemotherapy (intravenous infusion of 5-FU: $600 \mathrm{mg} / \mathrm{m}^{2}$ for $24 \mathrm{~h}$, and tegafur-uracil (UFT) given as $400 \mathrm{mg} / \mathrm{m}^{2}$ orally for five days. This regimen was based on the previously tested combination of continuous infusion of 5-FU and oral administration of UFT (30). Forty-two patients received short-course radiotherapy with chemotherapy over one week. The remaining 11 patients received long-course radiotherapy with chemotherapy for four weeks. The time interval between preoperative CRT and surgery was two to three weeks for short-course irradiation patients, and four to six weeks for long-course irradiation patients. There were no delays for either treatment regimen due to severe toxicity. All patients underwent standard surgery including total mesorectal excision, and received 5-FU-based adjuvant chemotherapy after surgery for six months to one year.

Histopathologic tumor regression. The degree of histopathologic tumor regression based on general rules for clinical and pathological studies on cancer of the colon, rectum and anus was classified into four categories: grade 0 , neither necrosis nor regressive changes; grade $1 \mathrm{a},>2 / 3$ vital residual tumor cells (VRTCs); grade 1b, 1/3-2/3 VRTCs; grade 2, <1/3 VRTCs; and grade 3, no VRTCs (31).

RNA extraction from endoscopic biopsy specimens. Pre-CRT endoscopic biopsy specimens were homogenized with a Mixer Mill MM 300 homogenizer (Qiagen Inc., Chatsworth, CA). Total RNA was isolated using an RNeasy Mini Kit (Qiagen Inc.) according to the manufacturer's instructions.

Microdissection and RNA extraction from FFPE specimens. As previously described (32), residual cancer and stromal cells were collected from FFPE specimens. Microdissected specimens were digested with proteinase $\mathrm{K}$ in lysis buffer containing Tris- $\mathrm{HCl}$, ethylenediaminetetraacetic acid, and sodium dodecyl sulfate, as previously published with minor modifications (33). RNA was purified by phenol and chloroform extraction.

cDNA synthesis. cDNA was synthesized with random hexamer primers and Superscript III reverse transcriptase (Invitrogen, Carlsbad, CA) according to the manufacturer's instructions.

Quantitative real-time polymerase chain reaction (RT-PCR). Quantitative RT-PCR analysis was carried out with the SYBRGreen PCR Master Mix (Applied Biosystems, Foster City, CA) using the Applied Biosystems 7500 real-time PCR System according to the manufacturer's instructions. Primers for HGF, cMET and ACTB ( $\beta$-actin) were designed with Primer3 software (Biology Workbench Version 3.2, San Diego Supercomputer Center, University of California, San Diego). Sequences are as follows: HGF-specific primers (sense, ATTTGGCCATGTTTTGACC; antisense, AGCTGCGTCC TTTACCAATG); cMET-specific primers (sense, AGGTGTG GGAAAAACCTGA; antisense, ATTCAGCTGTTGCAGG GAAG); and ACTB-specific primers (sense, ACAGAGCCT CGCCTTTGC; antisense, GCGGCGATATCATCATCC). PCR was performed in a final volume of $25 \mu \mathrm{l}$ with a SYBRGreen PCR Master Mix, using $1 \mu \mathrm{lDNA}$, and $400 \mathrm{nM}$ of each primer for the respective genes. Cycling conditions were $50^{\circ} \mathrm{C}$ for $2 \mathrm{~min}$ and $95^{\circ} \mathrm{C}$ for $10 \mathrm{~min}$ followed by 40 cycles at $95^{\circ} \mathrm{C}$ for $15 \mathrm{sec}$ and $60^{\circ} \mathrm{C}$ for $1 \mathrm{~min}$ each.

Relative expression levels of HGF and cMET. Relative gene expression levels were determined by the standard curve method. The standard curves and line equations were generated using five-fold serially diluted solutions of cDNA from qPCR Human Reference Total RNA (Clontech, Mountain View, CA) for HGF and c-MET. All standard curves were linear in the 
analyzed range with an acceptable correlation coefficient $\left(\mathrm{R}^{2}\right)$. The amount of target gene expression was calculated from the standard curve followed by quantitative normalization of cDNA in each sample using $\beta$-actin gene expression as an internal control. Target gene mRNA levels were given as ratios to $\beta$-actin mRNA levels. RT-PCR assays were done in duplicate for each sample and the mean value was used for calculation of the mRNA expression levels.

Immunohistochemistry for HGF and cMET. Sections (2-3 $\mu \mathrm{m}$ thick) were made from FFPE specimens. After deparaffinization and dehydration, specimens were brought to a boil in $10 \mathrm{mM}$ sodium citrate buffer for antigen unmasking. Specimens were then blocked and incubated with primary antibody overnight at $4^{\circ} \mathrm{C}$. Antibody staining was visualized using Envision reagents (Envision kit/HRP, Dako Cytomation, Denmark). All sections were counterstained with hematoxylin. HGF polyclonal antibody (rabbit polyclonal antibody raised against synthetic peptides of HGF, PAB3683, Abnova) and Met (c-Met) antibody (EP1454Y) (rabbit monoclonal to Met, ab51067, Abcam) were used at a dilution of 1:100 for detection using the labeled streptavidin-biotin method (LASB2 kit/HRP, Dako Cytomation). Negative controls were run simultaneously.

Colon cancer cell lines. CaCO2, SW480, LoVo and DLD1 derived from human colon adenocarcinomas, and CAR1 and RCM1 derived from human rectal adenocarcinomas were obtained from the Cell Resource Center for Biomedical Research, Institute of Development, Aging and Cancer, Tohoku University. Colorectal cancer cells were plated at a density of $10^{5}$ cells per well in 6-well plates (BD Falcon). These cell lines were grown in RPMI-1640 medium (Sigma-Aldrich, St. Louis, MO), supplemented with fetal bovine serum (FBS; $10 \%$ (v/v); Gibco BRL, Tokyo, Japan), glutamine (2 mM), penicillin $(1000 \mathrm{U} / \mathrm{ml})$, streptomycin $(100 \mathrm{~g} / \mathrm{ml})$ at $37^{\circ} \mathrm{C}$ in a $5 \% \mathrm{CO}_{2}$ incubator.

Irradiation, anti-HGF and SU11274 treatments. We selected the LoVo and SW480 cell lines, both of which highly express cMET by RT-PCR, for in vitro studies. These cell lines were seeded and incubated for $24 \mathrm{~h}$. These cell lines were then treated with monoclonal anti-human HGF antibody (clone 24612, R\&D Systems, Minneapolis, MN) at doses of 10 and $100 \mathrm{nM}$, and the small molecule inhibitor of the c-MET tyrosine kinase, SU11274 (Biaffin GmbH \& Co. KG, Kassel, Germany) at doses of 5 and $10 \mu \mathrm{M}$ for $24 \mathrm{~h}$ before irradiation. The SU11274 dose was selected based on previous studies $(29,34,35)$. LoVo and SW480 cells were given a 5-Gy dose of irradiation (CAX-150-20, Chubu Medical Co. Ltd). Total RNA was extracted five days after irradiation. HGF and cMET expression analysis was determined by real-time quantitative RT-PCR.

Matrigel invasion assay. Invasion assays were performed as described previously (36). Culture medium $(0.5 \mathrm{ml})$ containing the LoVo and SW480 cell suspensions $\left(5 \times 10^{4}\right.$ cells $\left./ \mathrm{ml}\right)$ was added to the plate chambers. The Matrigel Invasion Chambers and Control Inserts were incubated for $72 \mathrm{~h}$ at $37^{\circ} \mathrm{C}$ in the incubator.
Cell proliferation assay. The MTT [3-(4,5-dimethylthiazol2-yl)-2,5-diphenyltetrazoliumbromide] assay (Roche Diagnostics Corp., GmbH, Mannheim, Germany) was used to determine the degree of cell proliferation. Treated cells were seeded at $5 \times 10^{3}$ cells per well in 96-well flat-bottomed microtiter plates in a final volume of $100 \mu \mathrm{l}$ culture medium per well, and incubated in a humidified atmosphere $\left(37^{\circ} \mathrm{C}\right.$ and $\left.5 \% \mathrm{CO}_{2}\right)$. After $72 \mathrm{~h}$ culture, $10 \mu \mathrm{l}$ MTT labeling reagent (final concentration, $0.5 \mathrm{mg} / \mathrm{ml}$ ) was added to each well and the plates were incubated for $4 \mathrm{~h}$ in a humidified atmosphere. Solubilization solution $(100 \mu \mathrm{l})$ was added to each well and the plates were incubated overnight in a humidified atmosphere. After confirmation that the purple formazan crystals were completely solubilized, the absorbance of each well was measured by a SoftMax Pro microplate reader (Molecular Devices Corp., Sunnyvale, CA) at a wavelength of $562 \mathrm{~nm}$ corrected to $650 \mathrm{~nm}$. Each independent experiment was performed three times.

Statistical analysis. All statistical analyses were done using Stat View 5.0 for Windows (SAS Institute Inc., Cary, NC). Values of each target gene are expressed as median values (inter-quartile range) in tables or as means \pm standard error (SE) in figures. Associations between continuous variables and categorical variables were evaluated using Mann-Whitney U tests for two groups. The correlations between variables (levels of HGF and cMET gene products) were assessed with the Spearman rank correlation coefficient. Disease-free survival was calculated from the date of surgery to the date of disease recurrence. Survival was evaluated using the Kaplan-Meier method. The log-rank test was used to compare the cumulative survival durations in the patient groups. A non-parametric receiver operating characteristic (ROC) analysis was performed to calculate the best cut-off value for each gene expression level that would be predictive of distant recurrence and survival, using Medcalc 7.2 for Windows (Mariakerke, Belgium). P-values <0.05 were considered statistically significant.

\section{Results}

Patient characteristics and histopathological tumor regression. Fifty-three patients were included in this study. Their median age was 62 years (range, 37-78 years) and the male to female ratio was $4.3: 1$. The post-CRT pathological T stages were pT1 $(n=5)$, pT2 $(n=13)$, pT3 $(n=32)$ and pT4 $(n=3)$. Seventeen patients $(32.1 \%)$ had pathological lymph node metastases. Forty-five tumors $(84.9 \%)$ showed well or moderately differentiated adenocarcinoma histology. No patients had local recurrence. Patterns of distant recurrence were seen as liver and lung metastases in two patients, lung metastasis alone in five patients, and peritoneal metastasis in one patient. Histopathologic tumor regression grading was as follows: grade 0,0 patients; grade 1a, 11 patients; grade $1 \mathrm{~b}, 26$ patients; and grade 2, 16 patients. Forty-two patients received radiotherapy at doses of 20 Gy in 5 fractions over a week, and 11 patients received radiotherapy doses of $45 \mathrm{~Gy}$ in 18 fractions for 4 weeks (Table I). The median follow-up period was 49 months (range, 14-105 months).

HGF and cMET gene expression levels. Relative HGF and cMET mRNA levels in residual rectal cancer after CRT were 
Table I. Tumor characteristics and association of HGF and cMET gene expression with clinicopathological variables.

\begin{tabular}{|c|c|c|c|c|c|c|c|}
\hline & Number $(\%)$ & HGF in cancer & P-value & cMET in cancer & P-value & HGF in stroma & P-value \\
\hline \multicolumn{8}{|l|}{ Gender } \\
\hline Male & $43(81.1)$ & $0.213 \pm 0.043$ & \multirow[t]{2}{*}{0.339} & $0.457 \pm 0.091$ & \multirow[t]{2}{*}{0.471} & $0.047 \pm 0.023$ & \multirow[t]{2}{*}{0.545} \\
\hline Female & $10(18.9)$ & $0.276 \pm 0.073$ & & $0.773 \pm 0.358$ & & $0.021 \pm 0.015$ & \\
\hline \multicolumn{8}{|l|}{ Age, mean 62.5 years } \\
\hline$\leq 63$ & $21(39.6)$ & $0.212 \pm 0.044$ & \multirow[t]{2}{*}{0.472} & $0.413 \pm 0.174$ & \multirow[t]{2}{*}{0.365} & $0.015 \pm 0.013$ & \multirow[t]{2}{*}{0.158} \\
\hline$>63$ & $32(60.4)$ & $0.233 \pm 0.055$ & & $0.590 \pm 0.121$ & & $0.060 \pm 0.030$ & \\
\hline \multicolumn{8}{|l|}{$\mathrm{T}$ classification } \\
\hline $\mathrm{T} 1 / 2$ & $18(33.9)$ & $0.321 \pm 0.080$ & \multirow[t]{2}{*}{0.128} & $0.593 \pm 0.171$ & \multirow[t]{2}{*}{0.623} & $0.044 \pm 0.043$ & \multirow[t]{2}{*}{0.349} \\
\hline $\mathrm{T} 3 / 4$ & $35(66.1)$ & $0.175 \pm 0.037$ & & $0.478 \pm 0.125$ & & $0.041 \pm 0.019$ & \\
\hline \multicolumn{8}{|l|}{$\mathrm{N}$ classification } \\
\hline Absent & $36(67.9)$ & $0.252 \pm 0.049$ & \multirow{2}{*}{0.364} & $0.430 \pm 0.091$ & \multirow{2}{*}{0.946} & $0.033 \pm 0.019$ & \multirow{2}{*}{0.099} \\
\hline Present & $17(32.1)$ & $0.166 \pm 0.051$ & & $0.699 \pm 0.242$ & & $0.060 \pm 0.045$ & \\
\hline \multicolumn{8}{|l|}{ Lymphatic invasion } \\
\hline Absent & $14(26.4)$ & $0.173 \pm 0.053$ & \multirow[t]{2}{*}{0.919} & $0.482 \pm 0.167$ & \multirow[t]{2}{*}{0.775} & $0.020 \pm 0.013$ & \multirow[t]{2}{*}{0.472} \\
\hline Present & $39(73.6)$ & $0.243 \pm 0.047$ & & $0.530 \pm 0.123$ & & $0.050 \pm 0.026$ & \\
\hline \multicolumn{8}{|l|}{ Vascular invasion } \\
\hline Absent & $23(43.4)$ & $0.249 \pm 0.064$ & \multirow[t]{2}{*}{0.413} & $0.411 \pm 0.101$ & \multirow[t]{2}{*}{0.663} & $0.017 \pm 0.012$ & \multirow[t]{2}{*}{0.863} \\
\hline Present & $30(56.6)$ & $0.205 \pm 0.045$ & & $0.597 \pm 0.158$ & & $0.061 \pm 0.032$ & \\
\hline \multicolumn{8}{|l|}{ Postopetarive stage } \\
\hline $\mathrm{I} / \mathrm{II}$ & $33(62.3)$ & $0.270 \pm 0.053$ & \multirow[t]{2}{*}{0.132} & $0.451 \pm 0.095$ & \multirow[t]{2}{*}{0.887} & $0.036 \pm 0.020$ & \multirow[t]{2}{*}{0.350} \\
\hline III & $20(37.7)$ & $0.150 \pm 0.044$ & & $0.634 \pm 0.221$ & & $0.051 \pm 0.039$ & \\
\hline Histology & & & & & & & \\
\hline Well/moderate & $45(84.9)$ & $0.244 \pm 0.043$ & 0.262 & $0.586 \pm 0.115$ & 0.084 & $0.041 \pm 0.022$ & 0.368 \\
\hline Poorly/signet/mucinous & $8(15.1)$ & $0.115 \pm 0.051$ & & $0.146 \pm 0.101$ & & $0.046 \pm 0.034$ & \\
\hline Pathological response & & & & & & & \\
\hline Non-responder; $0 / 1 \mathrm{a} / 1 \mathrm{~b}$ & $37(69.8)$ & $0.254 \pm 0.048$ & 0.205 & $0.637 \pm 0.134$ & 0.093 & $0.055 \pm 0.027$ & 0.109 \\
\hline Responder; $2 / 3$ & $16(30.2)$ & $0.156 \pm 0.054$ & & $0.251 \pm 0.100$ & & $0.012 \pm 0.012$ & \\
\hline Radiotherapy & & & & & & & \\
\hline Short: $20 \mathrm{~Gy} / 4$ fractions & $42(79.2)$ & $0.270 \pm 0.044$ & 0.023 & $0.553 \pm 0.118$ & 0.981 & $0.041 \pm 0.029$ & 0.184 \\
\hline Long: $45 \mathrm{~Gy} / 25$ fractions & $11(20.8)$ & $0.049 \pm 0.015$ & & $0.372 \pm 0.163$ & & $0.048 \pm 0.023$ & \\
\hline Distant recurrence & & & & & & & \\
\hline Absent & $45(84.9)$ & $0.232 \pm 0.042$ & 0.762 & $0.464 \pm 0.103$ & 0.461 & $0.028 \pm 0.015$ & 0.018 \\
\hline Present & $8(15.1)$ & $0.180 \pm 0.082$ & & $0.818 \pm 0.320$ & & $0.122 \pm 0.095$ & \\
\hline
\end{tabular}

$\mathrm{T}$ and $\mathrm{N}$ categories indicate extent of the primary tumor and presence of lymph node metastasis. Values of each target protein are expressed as mean value \pm standard error.

$0.225 \pm 0.037$ (range, 0-1.232) and 0.518 \pm 0.100 (range, 0-3.477), respectively. The HGF expression level in stromal tissue was $0.042 \pm 0.019$ (range, 0-0.774).

Correlation between HGF and cMET gene expression. As shown in Fig. 1, HGF and cMET expression levels in residual cancer cells were significantly correlated (Spearman's $\varrho=0.387$, $\mathrm{P}=0.0068$ ). There was a significant positive correlation between the expression levels of cancer cell cMET and stromal HGF after CRT (Spearman's $\mathrm{Q}=0.459, \mathrm{P}=0.0047$ ). However, HGF expression in residual cancer and stromal tissue had no correlation.
Comparison of HGF gene expression between pre- and postCRT specimens. We obtained 12 pre-CRT biopsy specimens matched to microdissected specimens. HGF gene expression levels were very low in pre-CRT specimens. We excluded all the cases whose gene expression was not detected and lacked reproducibility. We observed that HGF gene expression levels in post-CRT specimens were significantly higher than in pre-CRT samples ( $\mathrm{P}=0.018)$ (Fig. 2).

Association of HGF and cMET expression levels with clinicopathological variables. Table I shows the association between the gene expression levels of HGF and cMET and clinico- 

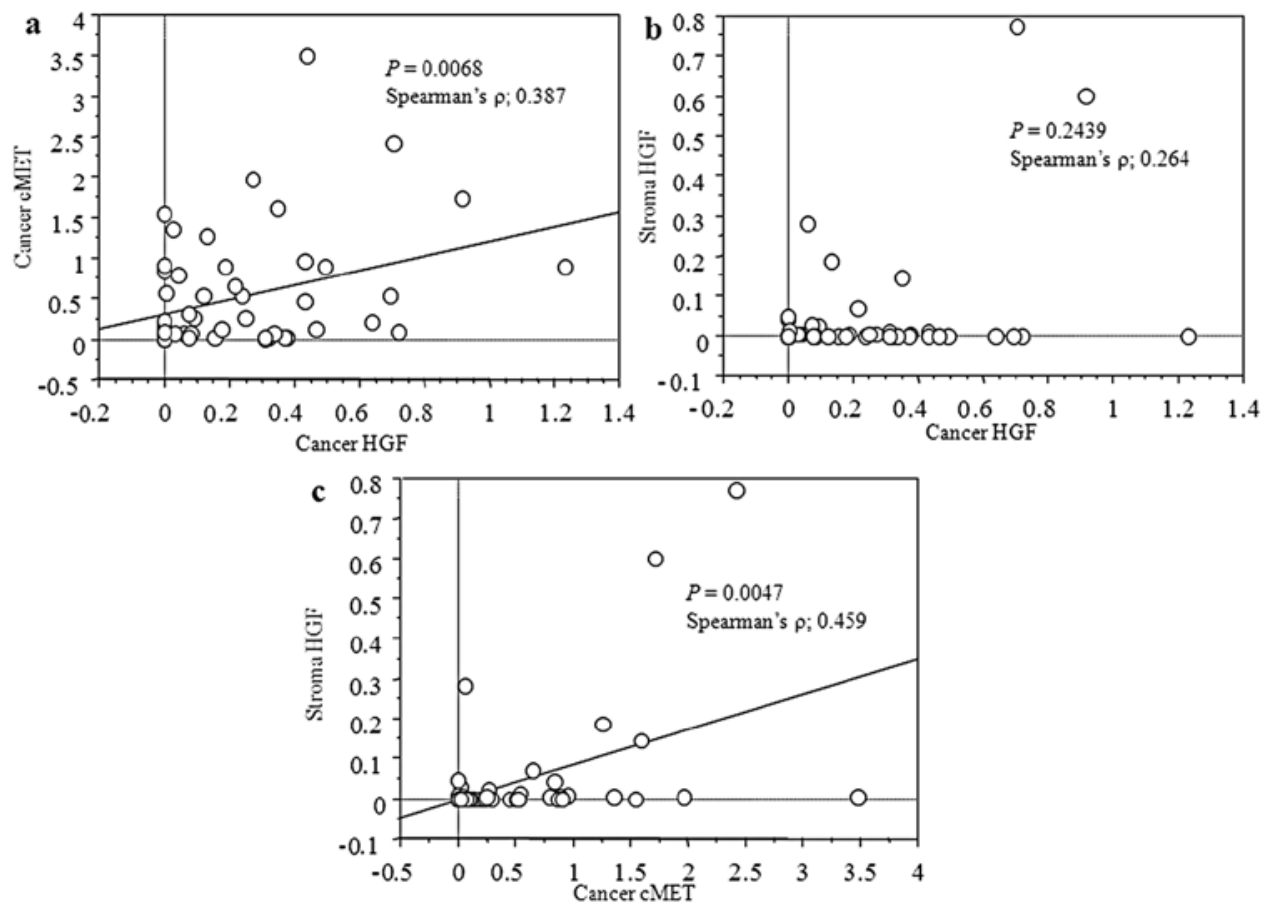

Figure 1. HGF and cMET expression are correlated in cancer and stromal tissues. There are significant correlations between cancer cell and stromal HGF expression, and between cancer cell cMET and stromal HGF expression.

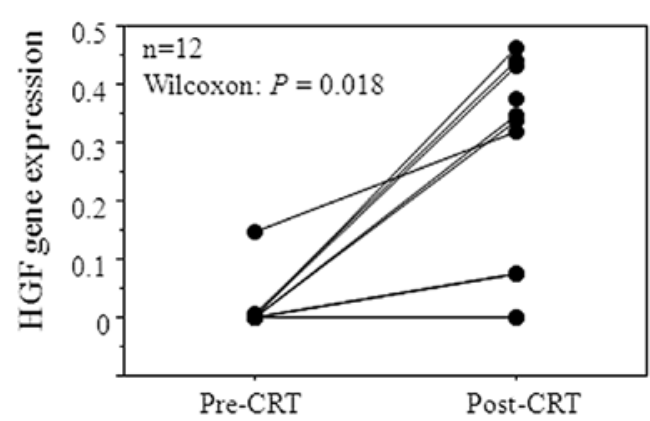

Figure 2. Comparison of HGF gene expression in pre- and post-CRT specimens. HGF mRNA in post-CRT specimens is significantly higher than in pre-CRT samples.

pathological variables. HGF expression in residual cancer was correlated with radiation dose $(\mathrm{P}=0.023)$. Without reaching statistical significance, the stromal HGF expression level was associated with tumor depth $(\mathrm{P}=0.099)$. Patients who developed distant recurrences had significantly higher gene expression levels of stromal HGF $(\mathrm{P}=0.018)$, but not cancer cell HGF and cMET, compared with those patients without recurrences. There was no significant association between the expression levels of these genes and other clinicopathological variables.

Predictive value of HGF and c-MET expression levels for prognosis. On the basis of these results, a receiver operating characteristic (ROC) analysis was used to identify cut-off values for HGF and cMET expression that were predictive of distant recurrence and survival. A non-parametric ROC analysis determined that the best cut-off values of HGF and cMET in residual cancer and HGF in stromal tissue were $0.187,0.877$ and 0.0018 for recurrence-free survival (RFS), and $0,0.877$ and 0.0405 for overall survival (OS), respectively. Fig. 3a-c shows the survival curve of patients subdivided on the basis of each cut-off value of cancer cell HGF, cMET and stromal HGF. Patients with elevated levels of cancer cell cMET and stromal HGF expression had significantly poorer prognoses than patients whose levels were below the cut-off values (cancer cell cMET: log-rank test, RFS; $\mathrm{P}=0.0103$, OS; $\mathrm{P}=0.0462$, stromal HGF: log-rank test, RFS; $\mathrm{P}=0.0017$, OS; $\mathrm{P}=0.022$ ). Additionally, patients with both cancer cell cMET and stromal HGF expression above the cut-off values had a significantly lower RFS and OS compared with the other group (log-lank test, RFS: $\mathrm{P}<0.0001$, OS: $\mathrm{P}=0.0006$ ) (Fig. 3d).

Immunohistochemistry for HGF and cMET. Fig. 4 shows immunohistochemistry staining for HGF and cMET in tissue samples from rectal cancer patients after CRT. HGF expression can be observed in the nuclei and cytoplasms of residual cancer cells (left panels). cMET expression, however, is located in the plasma membranes of residual cancer cells (right panels).

HGF and cMET expression in colorectal cancer cell lines. In order to investigate HGF and c-MET mRNA expression levels in six colorectal cell lines, CAR1, RCM1, CaCO2, SW480, LoVo and DLD1 were examined using RT-PCR and qPCR using Human Reference Total RNA as a positive control. HGF mRNA was barely detectable in the six colorectal cancer cell 

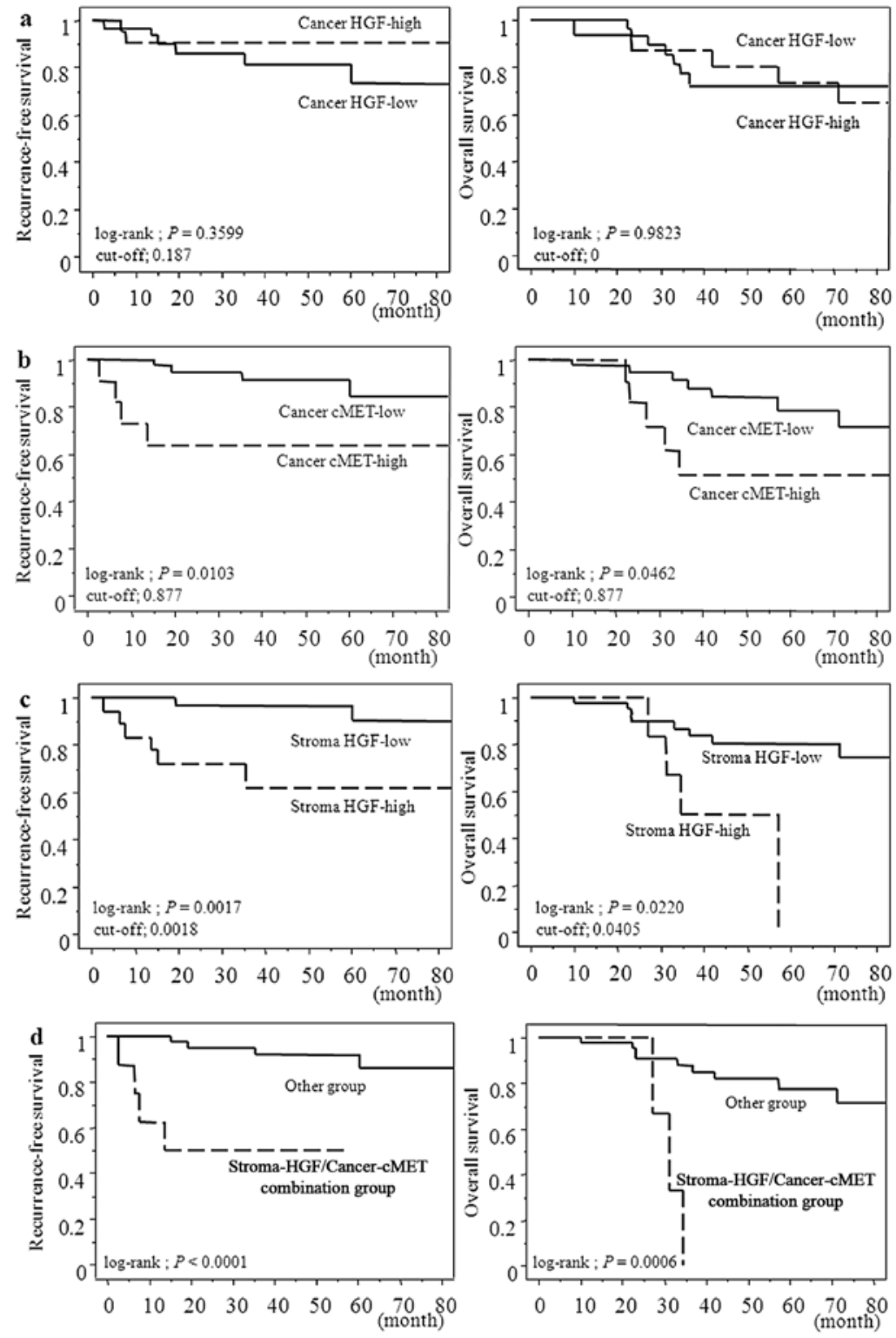

Figure 3. Recurrence-free and overall survival curves in patients segregated according to the indicated cut-off values. Cancer cell HGF (a), cancer cell cMET (b), stromal HGF (c) and cancer cell cMET/stromal HGF combinations (d).
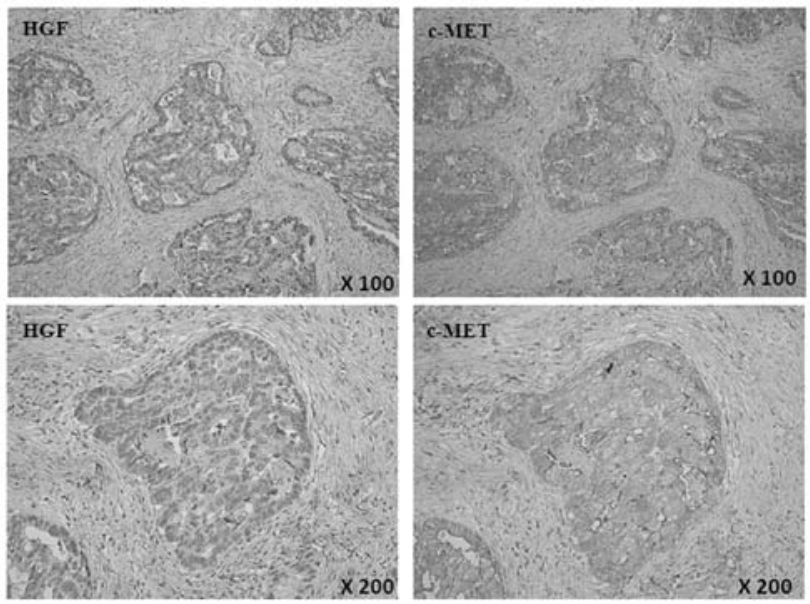

Figure 4. Immunohistochemistry for HGF and cMET in rectal cancer after CRT. HGF expression is observed in the nuclei and cytoplasms of residual cancer cells, whereas cMET expression is observed in the plasma membranes of residual cancer cells. lines. cMET was expressed by all of the colorectal cancer cell lines (Fig. 5a). We selected LoVo and SW480 for further in vitro study.

Inhibition of radiation induced HGF up-regulation treated by $S U 11274$. HGF expression was increased by irradiation at doses of 2.5 and 5 Gy. Remarkably, HGF up-regulation was inhibited by treatment with SU11274 prior to irradiation. In particular, a dose of $5 \mu \mathrm{M}$ SU11274 completely inhibited HGF expression after irradiation. Conversely, c-MET expression seemed not to be influenced by SU11274 treatment in conjunction with irradiation (Fig. 5b).

Matrigel invasion assay. We investigated whether pretreatment with anti-HGF and SU11274 before irradiation could suppress cell invasion. We observed that SW480 cell invasion was promoted by irradiation and pretreatment of anti-HGF $(100 \mathrm{nM})$, and that SU11274 $(10 \mu \mathrm{M})$ significantly suppressed 
a CAR1 RCM1 CaCO2 SW480 LoVo DLD1 HC

HGF

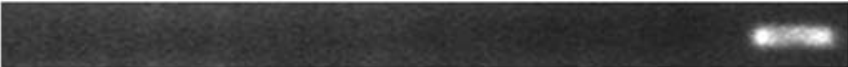

CMET

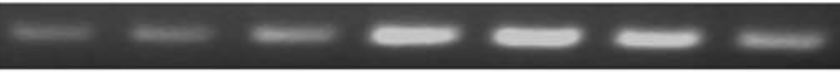

ACTB

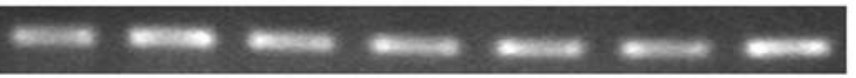

HC: qPCR Human Reference Total RNA
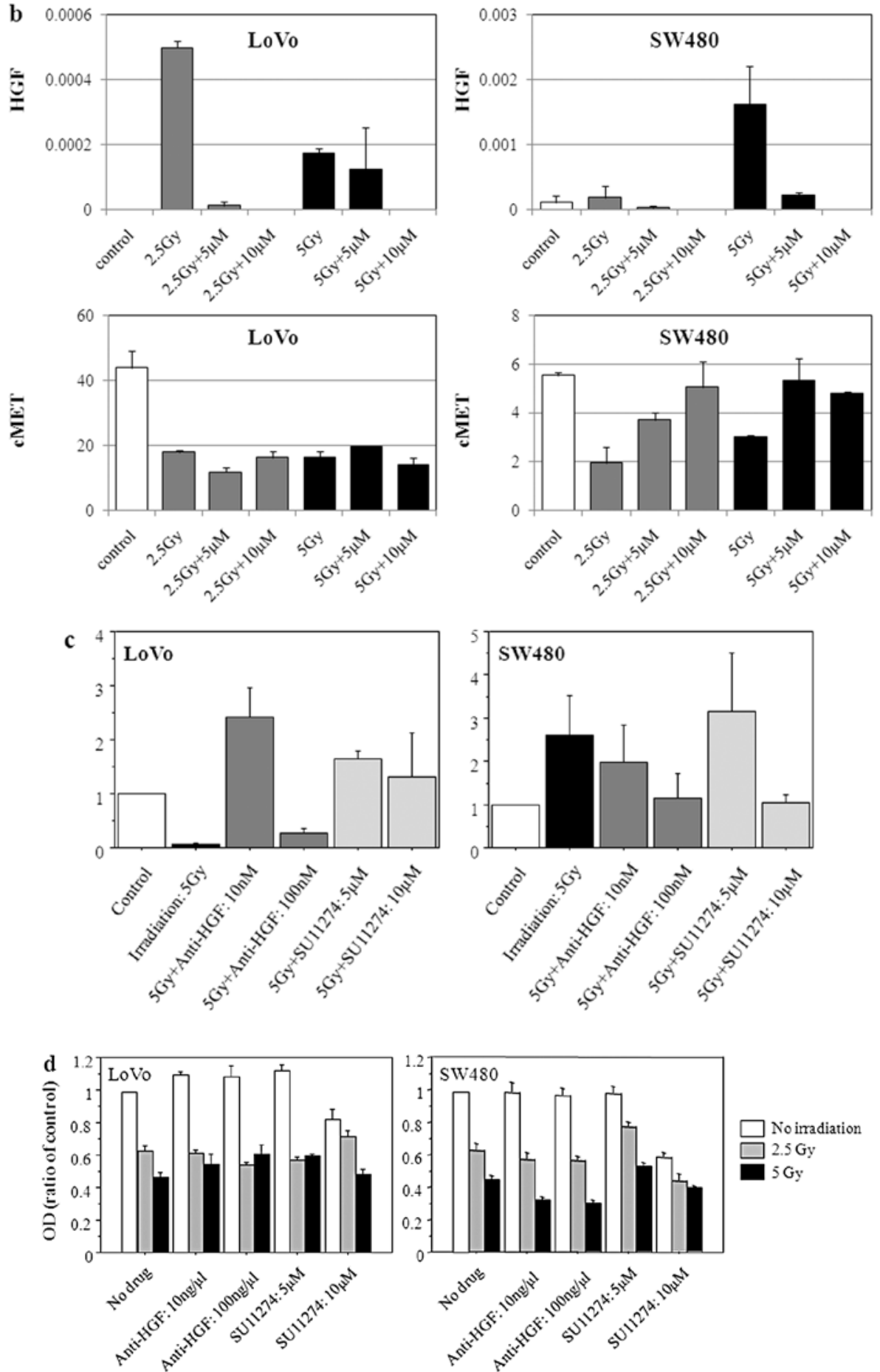

Figure 5. (a) CAR1, RCM1, CaCO2, SW480, LoVo and DLD1 were examined using RT-PCR and qPCR with Human Reference Total RNA as a control. HGF mRNA was barely detectable in the 6 colorectal cancer cell lines; however, cMET was expressed in all cell lines examined. (b) SU1127 inhibition of irradiationinduced HGF up-regulation. HGF expression was increased by irradiation at doses of 2.5 and 5 Gy. HGF up-regulation was inhibited by SU11274 treatment before irradiation. In particular, SU11274 at a dose of $5 \mu \mathrm{M}$ completely inhibited HGF expression after irradiation. (c) Matrigel invasion assay. We observed that SW480 cell invasion was promoted by irradiation, and that pretreatment of anti-HGF (100 nM) and SU11274 (10 $\mu$ M) significantly suppressed cell invasion. However, there was no marked effect of pretreatment in LoVo cells. (d) Proliferation assay. There was no significant effect on cell proliferation when irradiation was combined with pretreatment with anti-HGF or SU11274. Control, no treatment. 
cell invasion. However pretreatment of LoVo cells with antiHGF or SU11274 had no marked effect (Fig. 5c).

Cell proliferation assay. Fig. 5d shows the impact of anti-HGF and SU11274 treatment on cell proliferation in irradiated LoVo and SW480 cells. Treatment with anti-HGF had no effect on cell proliferation, although SU11274 at $10 \mu \mathrm{M}$ did decrease proliferation in non-irradiated LoVo and SW480 cells but not in irradiated cells.

\section{Discussion}

The present study is the first to report the evaluation of HGF expression in cancer cells as distinct from stromal tissue in rectal cancer patients. Current evidence indicates that the overexpression of HGF and its receptor cMET correlates with advanced stage and a negative prognosis in colorectal cancer. Furthermore, cMET mRNA overexpression in primary colorectal cancer tissue may be an important prognostic marker for early stage invasion and regional disease metastasis (37). We previously reported that preoperative serum HGF levels might be a useful prognostic marker in colorectal patients, and additionally, HGF protein levels in cancer tissue were significantly reflected by the levels in serum (38). In the present study, we also examined the correlations between the HGF and/or cMET mRNA levels in cancer tissue and serum HGF level, and the association of serum HGF with clinicopathological variables. However, we observed no significant correlation between them and clinicopathological variables except that the total radiation dose correlated with an elevated HGF level ( $\mathrm{P}=0.018$, data not shown). These data disagree with our findings described in an earlier report. However, HGF expression in bulky tumor tissues was evaluated in our previous report, whereas $\mathrm{HGF} / \mathrm{cMET}$ expression was more accurately measured in the present study because residual cancer cells were distinguished from stromal cells, which we believe accounts for the apparent discrepancy.

HGF expression is limited to mesenchymal tissue, including fibroblasts and mononuclear cells, while cMET expression is topographically localized to neoplastic epithelial cells $(20,22,26)$. Therefore, interactions between cancer cells and stromal cells are necessary for the activation of HGF/cMET signaling. Cancer cells are influenced not only by stromalderived HGF, but also facilitate HGF production in stromal cells. Cancer cell HGF secretion is induced by interleukin-1 $\beta$, basic fibroblast growth factor, platelet-derived growth factor and transforming growth factor- $\alpha$ (TGF- $\alpha$ ) $(17,39-41)$. In the present study, we observed that HGF up-regulation was induced by irradiation. Sheng-Hua et al reported that HGF levels showed a dose-dependent increase in human malignant glioma cell lines (8). Our results show irradiation directly promoted HGF expression in cancer cells, and subsequent cMET expression in cancer cells, in addition to promoting HGF expression in stromal cells. Taken together, the crosstalk between cancer cells and stromal cells, and $\mathrm{HGF} / \mathrm{cMET}$ signaling via autocrine and paracrine pathways, may be strongly associated with distant recurrence and poor prognoses in rectal cancer after preoperative CRT.

EMT is known as one of the mechanisms that promotes migration, invasion and metastasis of cancer cells. EMT facilitates cell migration and metastasis by the conversion of epithelial cancer cells to a more mesenchymal-like state $(42,43)$. Recently, it has been suggested that radiation may induce EMT $(9,11)$. HGF has also been described as inducing EMT, as well as TGF- $\beta(17,42)$. We observed that irradiated SW480 cells seemed to exhibit more aggressive proliferation compared with non-irradiated cells, and that pretreatment with anti-HGF or cMET inhibitors reduced cell invasion after irradiation in in vitro experiments, although not in LoVo cells. This could be due to a difference in responsiveness to irradiation between LoVo and SW480 cells, as shown in Fig. 5. Furthermore, inhibition of HGF or cMET before irradiation did not suppress cell proliferation. We speculate that HGF/ cMET inhibition may preferentially suppress cell migration rather than cell proliferation after irradiation. Additionally, our findings also suggest that radiation-induced EMT may be suppressed by inhibition of HGF/cMET.

Currently, preclinical and clinical studies using inhibitors of HGF and cMET signaling are ongoing in several cancers $(14,27)$. Although the outcomes of these studies have not been fully disclosed in public, a therapeutic strategy targeting the HGF/cMET signaling pathway may contribute to developing novel cancer treatments, especially in combination with cytotoxic agents, radiation and other tyrosine-kinase inhibitors.

In conclusion, the HGF/cMET signaling pathway is significantly associated with distant recurrence and a worse prognosis in rectal cancer after preoperative CRT. Additionally, radiationinduced HGF up-regulation may indicate distant recurrence and a poor prognosis. The inhibition of HGF/cMET to prohibit HGF up-regulation by radiation may suppress not only HGF autocrine signaling in cancer cells, but also HGF activation in stromal cells, and may be useful as a new strategy to reduce metastatic relapses and improve survival in patients with rectal cancer after preoperative CRT. However, data in this study should be interpreted with some caution. The major limitation was the small number of patients $(n=53)$, especially for patients with distant recurrence $(\mathrm{n}=8)$, and the retrospective nature of the study. A larger study population and a long-term follow-up will allow us to validate our conclusions.

\section{Acknowledgements}

The authors would like to thank Motoko Ueeda and Yuka Kato for providing excellent technical assistance. The authors declare no conflict of interest.

\section{References}

1. Sauer R, Becker H, Hohenberger W, et al: Preoperative versus postoperative chemoradiotherapy for rectal cancer. N Engl J Med 351: 1731-1740, 2004.

2. Bosset JF, Collette L, Calais G, et al: Chemotherapy with preoperative radiotherapy in rectal cancer. N Engl J Med 355: 1114-1123, 2006.

3. Guillem JG, Chessin DB, Cohen AM, et al: Long-term oncologic outcome following preoperative combined modality therapy and total mesorectal excision of locally advanced rectal cancer. Ann Surg 241: 829-838, 2005.

4. Camphausen K, Moses MA, Beecken WD, et al: Radiation therapy to a primary tumor accelerates metastatic growth in mice. Cancer Res 61: 2207-2211, 2001.

5. Wild-Bode C, Weller M, Rimner A, et al: Sublethal irradiation promotes migration and invasiveness of glioma cells: implications for radiotherapy of human glioblastoma. Cancer Res 61: 2744-2750, 2001. 
6. Schweigerer L, Rave-Frank M, Schmidberger H, et al: Sublethal irradiation promotes invasiveness of neuroblastoma cells. Biochem Biophys Res Commun 330: 982-988, 2005.

7. Qian LW, Mizumoto K, Inadome N, et al: Radiation stimulates HGF receptor/c-Met expression that leads to amplifying cellular response to HGF stimulation via upregulated receptor tyrosine phosphorylation and MAP kinase activity in pancreatic cancer cells. Int J Cancer 104: 542-549, 2003.

8. Sheng-Hua C, Yan-Bin M, Zhi-An Z, et al: Radiation-enhanced hepatocyte growth factor secretion in malignant glioma cell lines. Surg Neurol 68: 610-614, 2007.

9. Andarawewa KL, Erickson AC, Chou WS, et al: Ionizing radiation predisposes nonmalignant human mammary epithelial cells to undergo transforming growth factor beta induced epithelial to mesenchymal transition. Cancer Res 67: 8662-8670, 2007

10. Jung JW, Hwang SY, Hwang JS, et al: Ionising radiation induces changes associated with epithelial-mesenchymal transdifferentiation and increased cell motility of A549 lung epithelial cells. Eur J Cancer 43: 1214-1224, 2007.

11. Tsukamoto H, Shibata K, Kajiyama $\mathrm{H}$, et al: Irradiation-induced epithelial-mesenchymal transition (EMT) related to invasive potential in endometrial carcinoma cells. Gynecol Oncol 107: 500-504, 2007.

12. Fan S, Ma YX, Wang JA, et al: The cytokine hepatocyte growth factor/scatter factor inhibits apoptosis and enhances DNA repair by a common mechanism involving signaling through phosphatidyl inositol 3' kinase. Oncogene 19: 2212-2223, 2000.

13. Xiao GH, Jeffers M, Bellacosa A, et al: Anti-apoptotic signaling by hepatocyte growth factor/Met via the phosphatidylinositol 3-kinase/Akt and mitogen-activated protein kinase pathways. Proc Natl Acad Sci USA 98: 247-252, 2001.

14. You WK and McDonald DM: The hepatocyte growth factor/c-Met signaling pathway as a therapeutic target to inhibit angiogenesis. BMB Rep 41: 833-839, 2008

15. Sattler M and Salgia R: c-Met and hepatocyte growth factor: potential as novel targets in cancer therapy. Curr Oncol Rep 9: 102-108, 2007.

16. Herynk MH, Stoeltzing O, Reinmuth N, et al: Down-regulation of c-Met inhibits growth in the liver of human colorectal carcinoma cells. Cancer Res 63: 2990-2996, 2003.

17. Matsumoto $\mathrm{K}$ and Nakamura $\mathrm{T}$ : Hepatocyte growth factor and the Met system as a mediator of tumor-stromal interactions. Int J Cancer 119: 477-483, 2006.

18. Navab R, Liu J, Seiden-Long I, et al: Co-overexpression of Met and hepatocyte growth factor promotes systemic metastasis in NCI-H460 non-small cell lung carcinoma cells. Neoplasia 11: 1292-1300, 2009.

19. Grant DS, Kleinman HK, Goldberg ID, et al: Scatter factor induces blood vessel formation in vivo. Proc Natl Acad Sci USA 90: $1937-1941,1993$

20. Otte JM, Schmitz F, Kiehne K, et al: Functional expression of HGF and its receptor in human colorectal cancer. Digestion 61 : 237-246, 2000.

21. Bussolino F, Di Renzo MF, Ziche M, et al: Hepatocyte growth factor is a potent angiogenic factor which stimulates endothelial cell motility and growth. J Cell Biol 119: 629-641, 1992.

22. Takeuchi H, Bilchik A, Saha S, et al: c-MET expression level in primary colon cancer: a predictor of tumor invasion and lymph node metastases. Clin Cancer Res 9: 1480-1488, 2003.

23. Boccaccio $\mathrm{C}$ and Comoglio PM: Invasive growth: a MET-driven genetic programme for cancer and stem cells. Nat Rev Cancer 6 : 637-645, 2006

24. Nakamura T, Matsumoto K, Kiritoshi A, et al: Induction of hepatocyte growth factor in fibroblasts by tumor-derived factors affects invasive growth of tumor cells: in vitro analysis of tumorstromal interactions. Cancer Res 57: 3305-3313, 1997.
25. Jiang WG: Hepatocyte growth factor and the hepatocyte growth factor receptor signalling complex as targets in cancer therapies. Curr Oncol 14: 66-69, 2007.

26. Trusolino L and Comoglio PM: Scatter-factor and semaphorin receptors: cell signalling for invasive growth. Nat Rev Cancer 2: 289-300, 2002

27. Eder JP, Vande Woude GF, Boerner SA, et al: Novel therapeutic inhibitors of the c-Met signaling pathway in cancer. Clin Cancer Res 15: 2207-2214, 2009.

28. Underiner TL, Herbertz T and Miknyoczki SJ: Discovery of Small Molecule c-Met Inhibitors: Evolution and profiles of clinical candidates. Anticancer Agents Med Chem 16: 7-27, 2009.

29. Berthou S, Aebersold DM, Schmidt LS, et al: The Met kinase inhibitor SU11274 exhibits a selective inhibition pattern toward different receptor mutated variants. Oncogene 23: 5387-5393, 2004.

30. Yoshikawa R, Kusunoki M, Yanagi H, et al: Dual antitumor effects of 5-fluorouracil on the cell cycle in colorectal carcinoma cells: a novel target mechanism concept for pharmacokinetic modulating chemotherapy. Cancer Res 61: 1029-1037, 2001.

31. Japanese Society for Cancer of the Colon and Rectum: General Rules for Clinical and Pathological Studies on Cancer of the colon, Rectum, and Anus. 7th edition. Kanehara \& Co, Tokyo, 2006.

32. Saigusa S, Tanaka K, Toiyama Y, et al: Correlation of CD133, OCT4, and SOX2 in rectal cancer and their association with distant recurrence after chemoradiotherapy. Ann Surg Oncol 16: 3488-3498, 2009.

33. Bijwaard KE, Aguilera NS, Monczak Y, et al: Quantitative real-time reverse transcription-PCR assay for cyclin D1 expression: utility in the diagnosis of mantle cell lymphoma. Clin Chem 47: 195-201, 2001.

34. Sattler M, Pride YB, Ma P, et al: A novel small molecule met inhibitor induces apoptosis in cells transformed by the oncogenic TPR-MET tyrosine kinase. Cancer Res 63: 5462-5469, 2003.

35. Wang X,Le P, Liang C, et al: Potent and selective inhibitors of the Met [hepatocyte growth factor/scatter factor (HGF/SF) receptor] tyrosine kinase block HGF/SF-induced tumor cell growth and invasion. Mol Cancer Ther 2: 1085-1092, 2003

36. Yokoe T, Toiyama Y, Okugawa Y, et al: KAP1 is associated with peritoneal carcinomatosis in gastric cancer. Ann Surg Oncol 17: 821-828, 2010.

37. Kammula US, Kuntz EJ, Francone TD, et al: Molecular co-expression of the c-Met oncogene and hepatocyte growth factor in primary colon cancer predicts tumor stage and clinical outcome. Cancer Lett 248: 219-228, 2007.

38. Toiyama Y, Miki C, Inoue Y, et al: Serum hepatocyte growth factor as a prognostic marker for stage II or III colorectal cancer patients. Int J Cancer 125: 1657-1662, 2009.

39. Ostman A: PDGF receptors-mediators of autocrine tumor growth and regulators of tumor vasculature and stroma. Cytokine Growth Factor Rev 15: 275-286, 2004

40. Mueller MM and Fusenig NE: Friends or foes - bipolar effects of the tumour stroma in cancer. Nat Rev Cancer 4: 839-849, 2004.

41. Tamura M, Arakaki N, Tsubouchi H, et al: Enhancement of human hepatocyte growth factor production by interleukin-1 alpha and -1 beta and tumor necrosis factor-alpha by fibroblasts in culture. J Biol Chem 268: 8140-8145, 1993.

42. Tse JC and Kalluri R: Mechanisms of metastasis: epithelialto-mesenchymal transition and contribution of tumor microenvironment. J Cell Biochem 101: 816-829, 2007.

43. Bhowmick NA and Moses HL: Tumor-stroma interactions. Curr Opin Genet Dev 15: 97-101, 2005. 